\title{
On the Application of Death Penalty to Elderly Offenders in China
}

\author{
Bing Zou ${ }^{1}$ \\ ${ }^{1}$ School of Law, Southwest University, Chongqing, China \\ Correspondence: Bing Zou, School of Law, Southwest University, Chongqing 400715, China. E-mail: \\ zblaw99@163.com
}

Received: February 13, 2012

Accepted: February 14, $2012 \quad$ Online Published: June 1, 2012

doi:10.5539/jpl.v5n2p140

URL: http://dx.doi.org/10.5539/jpl.v5n2p140

The reaearch is supported by "the Fundamental Research Funds for Central Universities" (SWU1009026).

\begin{abstract}
First of all, the value orientation manifested in the exemption of death penalty for senile criminals in The Eighth Amendments of the Criminal Law should be affirmed. It should also be clearly laid down in legislation rather than being handled dynamically by the judicial branch. The upper age limit to the application of death penalty should be set at 75 years old. Besides, in order to ensure the balance within the criminal law system, some supplementary limitations should be attached. However, the limitation ruling out the situation in which particularly cruel means are used to kill a person doesn't seem so reasonable and needs to be further perfected.
\end{abstract}

Keywords: senile citizens' crimes, death penalty, upper age limit, limitations

\section{Introduction}

There has been a long-lasting debate on whether an upper age limit should be set to the application of death penalty in China. To sum up, the affirmative side holds that, in order to restrict and reduce death penalty and make the criminal law more human-based, an upper age limit should be attached to death penalty in accordance with some ancient and present experiences home and abroad by taking into account the forgivability in the crimes committed by senile people. The negative side, however, claims that due to the differences lying in senile and young people's crimes, a small number of senile criminals committing particularly severe crimes should also be sentenced to death. Regardless of these relevant debates, the discussions conducted previously were more confined to theoretical research, hence failing to draw wide attention from our society. Over 50 years since the foundation of People's Republic of China, the aged population has been on the rise, particularly in the 21st century which will witness a rapid development in the aging population and longevity of the aged population. An aging population has brought about a series of conflicts and pressure such as economic stress, supporting burden, insufficient social security and so on. This means that the number of crimes committed by senile citizens, especially by quite aged people, will be probably increased. It is the reason why the application of death penalty to this group has attracted increasing attention in the recent years. In The Eighth Amendments of the Criminal Law, it is clearly laid down in 2011 that death penalty shouldn't be applied to the criminals at or over 75 years old at trial except for the situation in which particularly cruel means are used to kill a person.

The cases in which death penalty is applied to senile criminals are rare in our legal practice. As for legislation, prior to the issuance of The Eighth Amendments of the Criminal Law, there had been no legislative document on a definite upper age limit to death penalty in China. It was laid down clearly in Article 21 of On the Implementation of the Criminal Policy of Tempering Justice with Mercy that the motivation, purpose, circumstances, results and repentance of senile criminals should be taken into full consideration in the case of their crimes and lenient punishments should be given in accordance with the dangerousness they may cause and the likeliness for them to commit another crime. Although this clarifies an institution to leniently treat senile criminals and seems to provide a basis for an upper age limit to death penalty, it is still not definite enough. Afterwards, 75 was set as the upper age limit to death penalty in the first and the second draft of The Eighth Amendments of the Criminal Law issued in 2010 and in the final draft in 2011 this remained the same as that in the second draft. As for this new rule, more fierce debates have been evoked. (Zhao, 2010) Generally, two issues are worth further studies: first, from the theoretical perspective, should senile criminals be exempt from death penalty? Second, from the technical perspective, how can a scientific and reasonable upper age limit be set to 
death penalty?

\section{The Theoretical Perspective: Should Senile Criminals be Exempt from Death Penalty?}

Currently in China, there are two reasons supporting the objection to exempting senile criminals from death penalty: First, due to the different characteristics of old citizens and juveniles, they cannot be treated equally as to the death penalty issue. Death penalty doesn't apply to juveniles because of their immature minds and strong versatility, while for old people who have gone though most of their life, with mature minds they are fully aware of their actions. Comparatively, old people should be less forgivable then juveniles, therefore, a different death penalty policy should apply to them accordingly. Second, along with the social and economic development and improved living quality, more people at the age of 75 still have full capacity for criminal responsibility and are likely to commit capital crimes. Third, old people's exemption from death penalty may be taken advantage of by other people for severe criminal activities. Fourth, this is a violation against the principle that everyone is equal before the law. Fifth, since death penalty has seldom been applied to senile criminals over 75 in legal practice, it is better to leave it to be flexibly handled within criminal policies than to absolutely abolish it (Dong, 2011). Finally, not all those nations retaining death penalty have made similar rules and some nations' legislative experience may not be of universality.

However, the above opinions may be argued against as follows:

\subsection{Old People in This Age Range are Commonly Characterized by Weakened Criminal Responsibility}

Following the same track as one's life, one's criminal responsibility will go through an objective process from birth, development to recession, forming a parabolic line along with the change in his age. In the juvenile period, as one's intelligence and psychology get mature, his criminal responsibility capacity grows mature as well; in the middle-age period, one's criminal responsibility capacity remains stable in a mature state; when he gets old, with physical and psychological recession, one's mind and action are less mature than before, hence having weaker, finally no, capacity of criminal responsibility. Certainly a few senile criminals may have strong cognitive and controlling ability when committing crimes, but law can only apply to a majority instead of exceptions.

2.2 Juveniles Below 18 as Well as Pregnant Women, Exempt from Death Penalty in China's Criminal Law, are Also Likely to Commit More Severe Crimes or be Taken Advantage of by Others

Besides, although efforts can be made to limit the application of death penalty to these two groups by adjusting criminal policies in practice, such an absolute principle represents a clear-cut stand and value orientation. The abolishment of death penalty involved in 13 economic crimes issued in The Eighth Amendments of the Criminal Law of China is also confronted with the same problem. If we only need judicial officers, criminal policies and discretionary power to limit the application of death penalty, the limitation and even the abolishment of it will be a false hypothesis.

\subsection{Equality, Above All, Means Sameness (Nonet, 1994)}

People's equality before the law should be more manifested in the application of law, that is, the same people in the same situations should be treated in the same or similar ways. Namely, with an upper age limit set for the application of death penalty, everyone's equality will be guaranteed as long as this law is fairly followed to treat the same or similar people in the same or similar way. Supposing two old people with the same crimes and physical conditions have got different legal punishments, the principle of everyone's equality is violated.

2.4 Although Not All the Nations Retaining Death Penalty Have Set an Upper Age Limit to Its Application, Many Have Laid Down Similar Regulations

Particularly in The Implementation of the Safeguards for Protecting Condemned Criminals' Rights approved of on May 24, 1989 by the Economic and Social Council of the United Nations and No. 1996/15 Resolution approved in July 1996, all member nations are called for to set an upper age limit to the sentence and implementation of death penalty in their criminal laws; in The American Convention on Human Rights, it is clearly laid down that death penalty cannot be applied to those over 70 (Gao, 2002). Therefore, when promoting its legal system, a nation is expected to make independent judgments and choices in conformity to their value demands based on their reality. At present, China is making great efforts to reduce and reasonably limit the application of death penalty. The limit to the application of death penalty to senile criminals is a strategic choice for China to promote its civilization in penalty and law.

\subsection{There are Diversified Bases for Limiting the Applicability of Death Penalty}

In the current debate on whether senile criminals should be exempt from death penalty in China, there is a voice comparing old people with juveniles below 18 and claiming that the same policy should be applied to both due to 
the same reason that they both have incomplete capacity for criminal responsibility. However, such an explanation is not necessarily reasonable. According to China's current criminal law, people over 16 have full capacity for criminal responsibility. At least in law, criminals between 16 and 18 years old are regarded to have full capacity for criminal responsibility. Besides, there is even death penalty legally set for the criminals between 14 and 16 years old. That is, juveniles between 14 and 18 are basically of full capacity for criminal responsibility for capital crimes. Thus, the principle that no death penalty can be applied to juveniles shouldn't be explained only by the capacity for criminal responsibility in the legal sense but more by versatility and coordination of rights. First of all, juveniles still have a long way to go in his life. With time passing by, their rebellion against the society may fade away as their outlooks on life and value get into shape. They still have enough time and opportunity to get corrected and finally return to society. In spite of the possibility of their committing capital crimes again after 18 years old, such a chance must be left for these immature young men in a nation's criminal policies. Besides, other branch laws set 18 years old as the division between people with full capacity for action and people with limited capacity for action. Seen from the human rights system in law, juveniles below 18 have no access to many legal rights, therefore it is unfair to deprive them of the upmost right to live. The principle that no death penalty can be applied to pregnant women is not necessarily related to their capacity for responsibility and versatility. Their babies are innocent, so such a principle is based on human sympathy as well as avoids national right being turned into a killing tool. As a result, the reasons are diversified for the limitation of the applicability of death penalty.

\subsection{The Purpose of Criminal Punishment Should be Taken into Consideration}

Whether it is necessary to apply death penalty to senile criminals should fall more into the category involving the purpose of punishment. Although the purpose to punish crimes and conduct justified retribution shouldn't be denied, modern criminal punishment should be more intended to prevent crimes. For senile criminals, a punishment against freedom can fully exert general and special preventive functions. In such a low-carbon era, a rational relationship of input and output should be taken into consideration when arranging criminal punishment. In order to accomplish the efficiency of criminal punishment, the frequency of employing it should be reduced as much as possible, which is also encouraged by the tolerance of our criminal law. In accordance with the economics and tolerance of criminal punishment, it is unnecessary to apply death penalty to senile criminals.

\subsection{Chinese Previous Experience Should be Based on}

In nearly every dynasty in Chinese history, there were some regulations and corresponding conventions reflecting leniency in punishment on senile criminals. In the Western Zhou Dynasty, old people at or over 80 were exempt from criminal responsibility and death penalty. In the Tang and Yuan Dynasty, death penalty was not applied to old people over 90. According to The Criminal Law of Republic of China issued in 1928 and amended in 1935, criminals over 80 could not be sentenced to death or life imprisonment. Although there was no age limit in New China's criminal law, the policy of tempering justice with mercy is followed in legal practice (2010), according to which death penalty was seldom applied to senile criminals, hence laying a solid basis for a lenient punishment on senile criminals.

In a word, it is an advance in nomocracy and civilization to forbid applying death penalty to senile criminals above 75 years old as is reflected in The Eighth Amendments of the Criminal Law, which is in conformity to the policy of remaining death penalty but employing it in a cautious way adopted in China. This is in line with China's reality as well as global trends, hence endowing China's criminal law both with modern colors and traditional spirits.

\section{The Technical Perspective: How to Exempt Senile Criminals from Death Penalty}

Several issues deserve attention concerning how to exempt senile criminals from death penalty: first comes a choice of the ways for judicial and legislative control. Some claim that regulation definitely laid down should give way to dynamic control about the application of death penalty to senile criminals with complicated situations in judicial practice taken into consideration. In this way, senile criminals can be exempt from death penalty in most cases, leaving room for exceptions. Second, supposing it is necessary to confirm this issue in legislation, how to define an upper age limit? What is the basis for the upper age limit of 75 stipulated in The Eighth Amendments of the Criminal Law and is it reasonable? Third, should all senile criminals be exempt from death penalty or some limitations should be attached? Fourth, is the exception reasonable of killing someone with particularly cruel means?

As to the above questions, the following are my opinions: 


\subsection{Regulations Should be Stipulated Definitely in Legislation}

Currently, due to the absence of corresponding regulations and universal standards followed by judicial departments at different places and different levels, a lack of unity among crime, criminal responsibility and punishment tends to arise. If judicial interpretation is expected to standardize it, the principle that criminal punishment should be prescribed by law would be violated. With an acceptability of the rationalization and value orientation to exempt senile criminals from death penalty, legislative control is more beneficial to the consistency of legal application, hence making it easier to realize the initial intention of law system.

\subsection{It is Ideal to Set the Upper Age Limit at 75 Years Old}

Seen from the existing legislative cases all over the world, the upper age limit covers a wide range including 60 (Mexico, Mongolia and so on), 65 (Russia, Kajakhstan and so on), 70 (Sudan, the Philippines and so on), 80 (Taiwan) and 90 (the Tang Dynasty and Yuan Dynasty). Currently in China, the average life span for male is 72 and for female is 74 , doubling the number in 1940s. It is claimed by some scholars that the upper age limit to death penalty should be set at 70, lower than the average life span (Zhao, 2010). However, with the rise of the average life span as well as relevant historical tradition, maybe 75 is fit better for the current reality, hence easier to be accepted by people and more beneficial for the stability of law. Of course, more empirical supports will be needed in sociology, psychology, medicine and other fields before we define such an age limit.

\subsection{Some Supplementary Limitations Should be Attached in Order to Guarantee the Balance Within the Criminal Law System}

A uniform pattern of no death penalty applied to senile criminals has been adopted in almost all instances of legislation. But I think some limitations should be laid down in the latest amendments to China's criminal law. The key doesn't really lie in the worry about how to severely punish some serious crimes with such a uniform article in our criminal law popular in some discussions, but in an issue of value orientation. Certainly, just like the case in juveniles and pregnant women, the risk of being illegally taken advantage of may be taken as well. What is really critical is that some additional limitations should be attached to ensure the balance within the criminal law system. Specifically, it is laid down in The Eighth Amendments of the Criminal Law that criminals over 75 may have their punishment mitigated or waived in the case of intentional crimes and should have their punishment mitigated or waived in the case of unintentional crimes. This rule hasn't attracted either much attention or dispute from the public. Comparatively, as for juvenile criminals below 18, it is laid down that those between 14 and 18 years old should have their punishment mitigated or waived. Obviously, the intensity of leniency seems different for the two groups. At least, it shows that, in the eye of the legislator, senile criminals are less forgivable than juvenile ones. On the premise of the acceptance of such a difference, it seems proper to add some limitations. Conversely, if a uniform pattern is believed to be applied to senile criminals, the relevant rule should be described as "criminals over 75 should have their punishment mitigated or waived". In addition, some additional limitations will enable this rule to be approved of in the game and compromise among different sides, hence promoting the limit to the application of death penalty as well as the rationalization and civilization of the whole criminal punishment system to the greatest degree in the current condition.

\subsection{The Limitation Ruling Out the Situation When Particularly Cruel Means are Employed Should be Further Improved Due to its Irrationality}

First of all, it is positive to confine the application of death penalty to the crimes depriving people's life since it is a proper way to reflect justice with such a "negation of negation" only in such a life-to-life case. Besides, although it can be logically inferred that killing someone with particularly cruel means should fall into the category of intentional crimes, a definite confinement should be given in legislation. In addition, according to China's law, death penalty should be based on extremely severe crimes. When judging whether a crime is extremely severe or not, "particularly cruel means" is just one of the elements, therefore it is partial to be confined to this standard. Finally, it is hard to set standards for particularly cruel means, laying hidden problems for judicial operation which are unavoidable regardless of judicial interpretation. Consequently, this rule can be amended as "death penalty shouldn't be applied to those who are over 75 years old with an exception of intentional crimes which are extremely severe.

\section{References}

The Supreme People's Court. (2010, February 8). On the Implementation of the Criminal Policy of Tempering Justice with Mercy. Retrieved from http://news.xinhuanet.com/legal/2010-02/10/content_12960937.htm

Dong, Yuting. (2011, September 8). It Should Be Discussed That No Death Penalty Is Applied to Senile Criminals over 75. Chinese Social Sciences Today 
Gao, Mingxuan \& Zhao, Bingzhi. (2002). New Issues on Criminal Law in the $21^{\text {st }}$ Century. (pp. 359-362). Chinese People's Public Security University Press.

Nonet. Selznick. Zhiming Zhang (translator). (1994). Law and Society in Transition. (pp.81-82).The Publishing House of China University of Politics and Law

Zhao, Bingzhi. (2010, October 27). Attention to Whether Senile Criminals Should be Exempt from Death Penalty. Legal Daily 